Estudios sobre el Mensaje Periodístico

ISSN-e: 1988-2696

https://dx.doi.org/10.5209/esmp.75556

\title{
Transformación, desafíos y tendencias en el periodismo actual
}

María-José Pérez-Serrano ${ }^{1}$

El periplo de este número monográfico de Estudios sobre el Mensaje Periodístico ha sido largo. Aun así, desde que echó a andar y en la esfera global, han pasado tantas cosas que pareciera que el tiempo ha transcurrido distinto al que marca el calendario. La población mundial ha tenido que cambiar, entre otras cosas, sus ritmos y costumbres. Y, en el sector de los medios de comunicación $\mathrm{y}$, también, en quienes nos dedicamos a la docencia y la investigación del Periodismo, estos cambios han impactado de manera drástica.

Se ha dicho de forma recurrente que los medios de comunicación, y las estructuras orgánicas y económicas que los sostienen, son muy permeables a esas transformaciones, puesto que, como parte del tejido social, viven, construyen y son testigos de los avatares de la historia diaria de la comunidad que les sirve de hábitat. Por lo tanto, los investigadores en Ciencias Sociales y, en ellas, los dedicados al Periodismo estamos acostumbrados a analizar una realidad en transformación; un hoy, que presenta desafíos continuos en los objetos de estudio, en modelos de negocio, en narrativas y en técnicas; una actualidad, donde se atisban tendencias y es imprescindible, para caminar por ellas, plantear prospectivas. Este es el Periodismo actual que se disecciona en este número: poliédrico, rico en experiencias y riguroso en forma $\mathrm{y}$ fondo.

Hipertextualidad, multimedialidad y bidireccionalidad en los soportes lógicos para dispositivos móviles: una revisión crítica adopta el "enfoque del Periodismo pensado para ser distribuido en dispositivos móviles". Planteamiento técnico que, compaginado con un análisis de índole cartográfico, se aborda el artículo titulado Periodismo y tecnología, tendencias de investigación y propuestas.

Por otro lado, La Realidad Aumentada para la cobertura informativa de las Elecciones Generales en España (2019). El caso del Grupo Atresmedia, que estudia el "rol que desempeña esta herramienta dentro de la narración informativa de Antena 3 y La Sexta", y Análisis de la implementación de la Realidad Aumentada como herramienta interactiva en medios impresos americanos, que concluye que "los ejemplares analizados de Burnaby NOW (Canadá) y Kids News (Argentina) se suman al proceso de renovación y reinvención del ecosistema mediático", abren el espectro a diferentes tipos de output informativos

¿Infografías en los reportajes en vídeo $360^{\circ}$ ? La integración de la visualización de la información en entornos esféricos plantea que "la 'infografía inmersiva' se encuentra en una fase temprana de desarrollo en la que todavía no se ha explotado todo su potencial". Ruta UX para comunicadores. Un modelo para el desarrollo de productos digitales desde la mirada de la comunicación emplea una metodología enmarcada en "el aprendizaje experiencial siguiendo las fases de testear, empatizar, investigar, diseñar y prototipar". Y Visibilidad web en buscadores profundiza en "los factores SEO que utilizan la información periodística en los motores de búsqueda".

En un bloque más vinculado a estructura y negocio, La nueva prensa cooperativista en la Europa occidental sostiene que "estos medios aportan un enfoque innovador a la empresa periodística convencional y que continúan parcialmente la herencia de la comunicación alternativa". En Tendencias de cambio en el comportamiento juvenil ante los media: Millennials vs Generación Z, a través de encuestas a "1.908 jóvenes de dos generaciones, millennials y generación $\mathrm{Z}$, se muestra cómo se está produciendo el cambio de paradigma comunicacional". Emergencia, innovación y consolidación de nuevos modelos para el periodismo digital: estudio de los casos de El Confidencial, elDiario.es e infoLibre tiene como objeto "identificar diferentes políticas de gestión de la interacción, concluyendo un muy reducido peso de estas en la predicción del número de seguidores". La narrativa de viajes como modelo de negocio ahonda, desde el modelo CANVAS, en "identificar los factores de éxito de su modelo de negocio desarrollado por Diario de un nómada". Y esa perspectiva emprendedora se completa en Análisis de la formación universitaria en periodismo freelance: la perspectiva de los profesionales españoles, que enfatiza en "esta forma de autoempleo ha experimentado un gran crecimiento en los últimos años".

Hay también varios artículos donde se valoriza la perspectiva ética del Periodismo en la actualidad y en diferentes países. El lugar del periodismo ciudadano desde la credibilidad y la confianza da a conocer la razón por la cual "el término cada vez se utiliza me-

Universidad Complutense de Madrid (España)

E-mail: mariajoseperezserrano@pdi.ucm.es 
nos, resituándolo en el espacio que le corresponde aun cuando las acciones informativas de la ciudadanía se han diversificado y multiplicado exponencialmente". El método Delphi sirve, en Los desafios éticos del periodismo en la era de la inteligencia artificial, para ofrecer un discurso sobre este tema de estudio. Credibilidad en disputa en periodismo digital tiene como referente varias iniciativas digitales de fact-checking que han proliferado en Brasil. Y el enfoque internacional, con una metodología basada en el análisis de contenido, se completa con Desinformación online y fact-checking en entornos de polarización social: el periodismo de verificación de Colombiacheck, La Silla Vacía y AFP durante la huelga nacional del $21 \mathrm{~N}$ en Colombia.

Conjugando elementos de ética y de narrativa, Más allá de los márgenes: repensar el rol éticopolitico del "fuera de campo" en la narrativa periodistica analiza "el trabajo del documentalista y teórico del audiovisual, Jean-Louis Comolli y se ejemplifica a través de las estrategias narrativas y compositivas del documental Agarrando pueblo (1978)". Nuevas narrativas en los cibermedios: de la disrupción a la consolidación de formatos y características sirve para "identificar los formatos y las características que se han desplegado con el de-

María-José Pérez-Serrano. Licenciada en Periodismo; doctora en Ciencias de la Información; Premio Extraordinario de Doctorado y MBA, con la especialidad de Gestión Financiera. Especialista en gestión, organización y dirección de empresas informativas, está acreditada por la ANECA como Profesora Titular; cuenta con el Certificado I3 y tiene un sexenio de sarrollo narrativo". Periodismo y nuevas narrativas. Storytelling como formato de difusión informativa en redes sociales "demuestra que los diferentes formatos están estrechamente ligados a la actualidad e inmediatez informativa, en los que los usuarios pueden participar activamente en la construcción de la realidad". Y, también, Periodismos y narrativas emergentes: diarios nativos digitales españoles en YouTube diagnostica prácticas crossmedia y la habilitación de canales basados en las áreas de especialización periodística. Por último, en el Reportaje sonoro y podcasting, el despertar de un género durmiente en España. El caso de Podium Podcast se decanta por estudiar los géneros en la radio utilizando, para ello, una metodología mixta.

Como se puede observar en estas pocas pinceladas, los 21 artículos que componen la sección de Estudios (más los que forman la sección de Investigaciones y Documentos), se podrían dividir en función de su temática o su método, o de la procedencia académica o de origen de sus autores, pero quizás sea reduccionista encasillar tanto trabajo en etiquetas. Por eso, vamos a quedarnos solo con una marca: aquella que pone en valor su fuerza académica por dar en el Periodismo un paso más y desentrañar sus más especiales perspectivas.

investigación. Pertenece al Departamento Periodismo y Comunicación Global de la Facultad de Ciencias de la Información de la Universidad Complutense de Madrid. Además, es coordinadora de la sección Periodismo y Nuevos Medios de la AE-IC. ORCID:

https://orcid.org/orcid.org/0000-0002-2190-7619 